\title{
Morphological modification of low-density polyethylene for enhanced Phanerochaete chrysosporium surface bioerosion
}

\author{
Shloka V. Janapaty ${ }^{1}$ \\ ${ }^{1} \mathrm{Fu}$ Foundation School of Engineering and Applied Science, Columbia University, 116th \& \\ Broadway, New York, NY, United States
}

\author{
ARTICLE HISTORY \\ Compiled January 5, 2021
}

\begin{abstract}
Disposal of end-of-life low density polyethylene (LDPE) in landfill structures poses an ecological threat through leaching, fragmentation, and additive migration. The present study examines the mycodegradation of morphologically modified lowdensity polyethylene (LDPE) films by Phanerochaete chrysosporium, a lignolytic basidiomycete. Three physicochemical treatments were employed: thermo-oxidation, chemical etching, and synthetic leachate. Surface area imaging over 6 days revealed bioerosion, qualifying $P$. chrysosporium as a suitable agent for LDPE degradation. Analysis of crystallinity indices showed that thermo-oxidation and chemical etching induced conformational changes to the polymer surface, increasing surface area reduction by $19 \%$ and $22 \%$ respectively. Synthetic leachate (SL) was associated with a $36 \%$ increase in surface area reduction. In combination, the three treatments achieved a $99 \%$ increase in surface area reduction. These trends were corroborated by gaseous evolution in parallel, attributable to the metabolization of fungal isolates. Electrospray Ionization Fourier Transform (FTMS + pESI) profiles observed signs of leachate remediation and organic byproducts. A molecular mechanism for degradation was subsequently proposed based on SL composition.
\end{abstract}

\section{KEYWORDS}

mineralization, secondary metabolism, cross-linking, ligninolysis, bioremediation

\section{Introduction}

Low density polyethylene (LDPE) is a versatile plastic of immense industrial utility. However, of the 64 million metric tons manufactured every year, only 5.7 percent is recycled [1,2]. Other methods of disposing end-of-life LDPE are often unsafe or counterproductive [3]. As a result, most LDPE accumulates in landfills, where its carbon-to-carbon backbone and branched structure render it recalcitrant and pose an ecological threat through leaching, fragmentation, and additive migration $[4,5]$. In 1978, Hiroyuki et al. proposed two solutions to this polymeric design challenge: engineering biodegradable materials and enhancing microbial degradation [6]. While the former holds long-term potential, this study focuses on biodegradation as a means of addressing LDPE entering existing solid waste structures.

Previous literature has established that fungi exhibit higher enzyme activity than bacteria [7]. Microbial species in genera Aspergillus, Ideonella, and Trichoderma are 
particularly effective at eroding the surface of tertiary sites on polyethylene [8-11]. Studies have also reported that small product degradation is easier than large product degradation, in addition to considering morphological changes to polymer surfaces [7]. However, literature on the impact of physicochemical surface pretreatment on biodegradation is scarce. The objective of this investigation is to enhance LDPE biodegradation by inducing morphological changes to its surface.

\subsection{Phanerochaete chrysosporium}

Phanerochaete chrysosporium is a white-rot basidiomycete that degrades aromatic hydrocarbons, predominantly lignin, under aerobic conditions [12-14]. Lignin's aliphatic side chains share structural similarities with LDPE, leading to the novel hypothesis that $P$. chrysosporium's two key enzymes, lignin peroxidase $(\mathrm{LiP})$ and manganese peroxidase $(\mathrm{MnP})$, may possess the ability to mineralize LDPE $[15,16]$. These enzymes generate $\mathrm{H}_{2} \mathrm{O}_{2}$ through an oxidation reaction to degrade organic pollutants, viable in $\mathrm{pH}$ range $2.5<\mathrm{pH}<6$ and over a wide range of temperatures, 25 to $60{ }^{\circ} \mathrm{C}[16,18]$. It is capable of growth in both shallow stationary cultures and agitated flask cultures [17].

P. chrysosporium metabolization of various contaminants is shown in Table 1. During secondary metabolism, biofilm formation occurs based on nutrient, oxygen, and trace metal availability [18-22].

Table 1. P. chrysosporium Metabolization

\begin{tabular}{lc}
\hline Substrate & Mineralization \\
\hline Organics & $\mathrm{CO}_{2}$ \\
Nitrogen Compounds & $\mathrm{NO}_{3}^{2-}$ \\
Hydrogen Compounds & $\mathrm{H}_{2} \mathrm{O}$ \\
Heavy Metals & Ion Adsorption \\
\hline
\end{tabular}

This study examines the degradation of morphologically modified LDPE using $P$. chrysosporium. The selection of physicochemical pre-treatments is described in the section that follows.

\subsection{Morphological Treatments}

LDPE consists of long aliphatic chains with repeating $\mathrm{CH}_{2}$ - units [4], resulting a closely-packed, branched network. Under normal conditions, this structure interferes with crystallization. However, Drummond et al. found a rise in melting crystallites in the $110 \mathrm{C}$ to $120{ }^{\circ} \mathrm{C}$ temperature regime [23,24].

Mijovic also reported that chemical etching impacts polymer mechanical properties and surface area roughness, facilitating subsequent fungal anchorage [25].

Landfill leachate is wastewater formed by the percolation of rainwater through a landfill. A high C:N ratio and substrate adsorbability suggest activation of the secondary enzymatic mechanism necessary for $\mathrm{LiP}$ and $\mathrm{MnP}$ secretion [26,27].

The author also examined 11 other pretreatment methods in preliminary experiments, omitted for brevity. 


\section{Methods}

The aim of this study was to identify physicochemical treatment combinations that maximize LDPE mycodegradation: $P$. chrysosporium inoculation, synthetic leachate, etching, and thermo-oxidation. Table 2 displays the configuration.

Table 2. Treatment Combinations

\begin{tabular}{lccccc}
\hline \multirow{5}{*}{ Group } & LDPE & PC & Thermo-oxidation & Etching & Synthetic Leachate \\
\cline { 2 - 6 } Control $^{1}$ & $\times$ & & & & \\
1 & $\times$ & $\times$ & & & \\
2 & $\times$ & $\times$ & $\times$ & $\times$ & \\
3 & $\times$ & $\times$ & $\times$ & $\times$ & \\
4 & $\times$ & $\times$ & $\times$ & & $\times$ \\
5 & $\times$ & $\times$ & $\times$ & $\times$ & $\times$ \\
6 & $\times$ & $\times$ & $\times$ & $\times$ & $\times$ \\
7 & $\times$ & $\times$ & $\times$ & & $\times$ \\
8 & $\times$ & $\times$ & $\times$ & & \\
\hline
\end{tabular}

${ }^{1}$ No morphological or mycoremedial treatment.

\subsection{Experimental}

LDPE was obtained from commercially-available films of uniform thickness $(\sim 15 \mu \mathrm{m})$ and cut into strips of surface area $115 \mathrm{~mm}^{2}$ and mass $3 \mathrm{mg}$. The films were then sterilized with a bleach-water solution.

\subsubsection{Thermo-oxidation}

LDPE was heated in a convection oven at $120{ }^{\circ} \mathrm{C}$ for 4 minutes. The surface area reduction for each film as a result of this procedure was recorded, averaging $7 \%$.

\subsubsection{Chemical Etching}

Anhydrous citric acid was used to prepare a $30 \%$ citric acid solution, in which LDPE films were immersed for 10 minutes. After removal from solution, the solvent was allowed to evaporate off the polymer surface. In preliminary experiments, LDPE rinsed with distilled water proved less susceptible to biodegradation, so this procedure was eliminated.

\subsubsection{Synthetic Leachate}

Synthetic leachate (SL) composition was adapted from Azhar et al. to simulate landfill wastewater conditions [28] at $\mathrm{pH} 5.6$ and comparable COD:TN:TP ratios. SL was boiled and set with small amounts of potato-dextrose agar (PDA) for 24 hours. The $\mathrm{C} / \mathrm{N}$ ratio of the SL-PDA medium was approximately $25: 1$ with a starting $\mathrm{pH}$ of 5.7.

\subsubsection{P. chrysosporium Inoculation}

P. chrysosporium was incubated on a PDA slant at $27^{\circ} \mathrm{CC}$ for 24 hours. After sporulation, SL-PDA plates were subsequently inoculated with $2 \cdot 10^{7}$ fungal spores per gram.

LDPE films were placed in their corresponding media (PDA or SL-PDA) for an observation period of 6 days every 12 days. After the experimental procedure was termi- 
nated, LDPE was retrieved using filter paper, sterilized with a bleach-water solution, and analyzed for degradation.

\subsection{Surface Area and Crystallinity}

Surface area and crystallinity changes were quantified over 6 days using the Java image-processing program, Image J. Surface area reduction indicates polymer bioerosion, and crystallinity is associated with spherulitic nucleation and roughness in LDPE morphology [29]. Statistical analyses were performed by StatPlus.

\section{3. $\mathrm{CO}_{2}$ Evolution}

It is well-known that polyethylene degradation yields gaseous byproducts, predominantly $\mathrm{CO}_{2}$, due to the increase in low molecular weight material and reduction in carbonyl groups. $\mathrm{CO}_{2}$ evolution was measured by water displacement in a pneumatic trough apparatus.

\subsection{Electrospray Ionization Fourier Transform (FTMS + pESI)}

Changes in leachate composition in PDA, SL-PDA, and Group 8 samples over 12 days were investigated using an Orbitrap and fourier transform (FTMS + pESI) techniques at $5 \mu \mathrm{L} / \mathrm{min}$ and 60,000 resolution. ESI was performed at $30 \mathrm{~V}$ capillary voltage and $60 \mathrm{~V}$ tube voltage, low mass conditions.

Compounds were identified by the ChemBioDraw software $( \pm 0.0001 \mathrm{~m} / \mathrm{z}) . \mathrm{NH}_{4}{ }^{+}$, $\mathrm{NO}_{3}{ }^{2-}$, and $\mathrm{NO}_{2}{ }^{-}$data were corroborated by ancillary indicator tests.

\section{Results and Discussion}

All results concern the identification and analysis of morphological pre-treatments for enhanced LDPE biodegradation and were statistically significant $(p>0.05)$.

\subsection{Crystallinity Index}

Figure 1 shows trends in relative percentage crystallinity induced by thermo-oxidation (Group 2) and thermo-oxidation with etching (Group 4).

For both surface modifications, the initial spike occurred on Day 1 after pretreatment. Thermo-oxidation causes a cross-linking reaction where tie chains undergo chain scission and cilia chains recrystallize [30]. The increase in cross-linking is likely responsible for the sharp increase in percentage crystallinity. Elongation of the amorphous region was visually observed, in agreement with the findings of Veitmann et al. [31].

Chemical etching performed prior to thermo-oxidation further enhanced crystallization, a result shared by Miyagawa et al. who corroborated that chemical etching crystallizes amorphous regions [30].

After initial treatment, the population of crystallites declined due to surface bioerosion as a function of exposure time. Percentage crystallinity remained fairly unchanged by $P$. chrysosporium and SL, and when there were no treatments. 


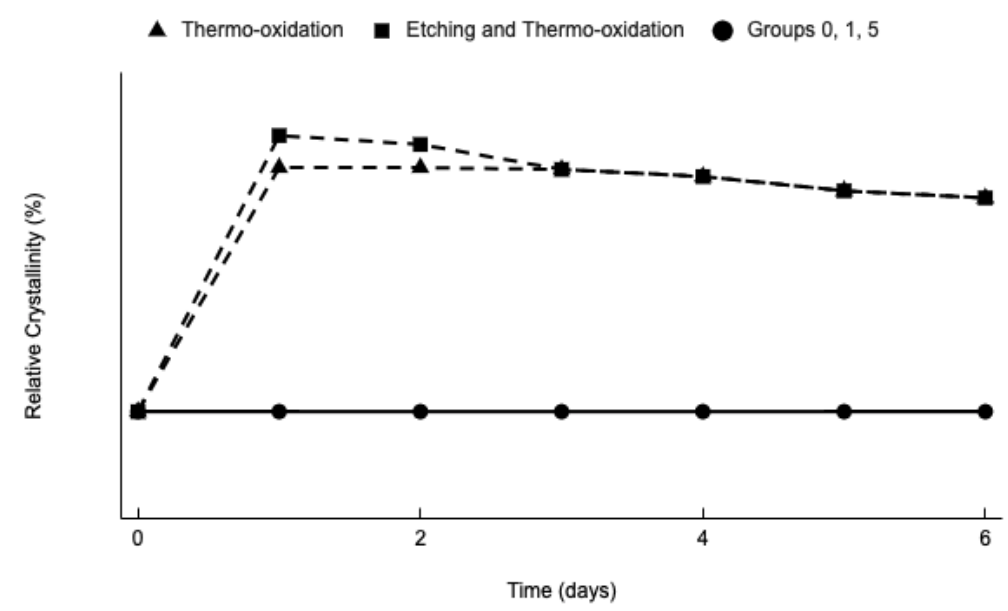

Figure 1. Trends in relative percentage crystallinity induced by thermo-oxidation (Group 2) and thermooxidation with etching (Group 4).

\subsection{Surface Area Reduction and Gaseous Evolution}

Figure 2 tracks the change in average surface area reduction of $3 \mathrm{mg}$ LDPE films after 6 days, with a baseline comparison against Group 1. Prolonged exposure to $P$. chrysosporium (Group 1) yielded a surface area reduction of $5 \%$.

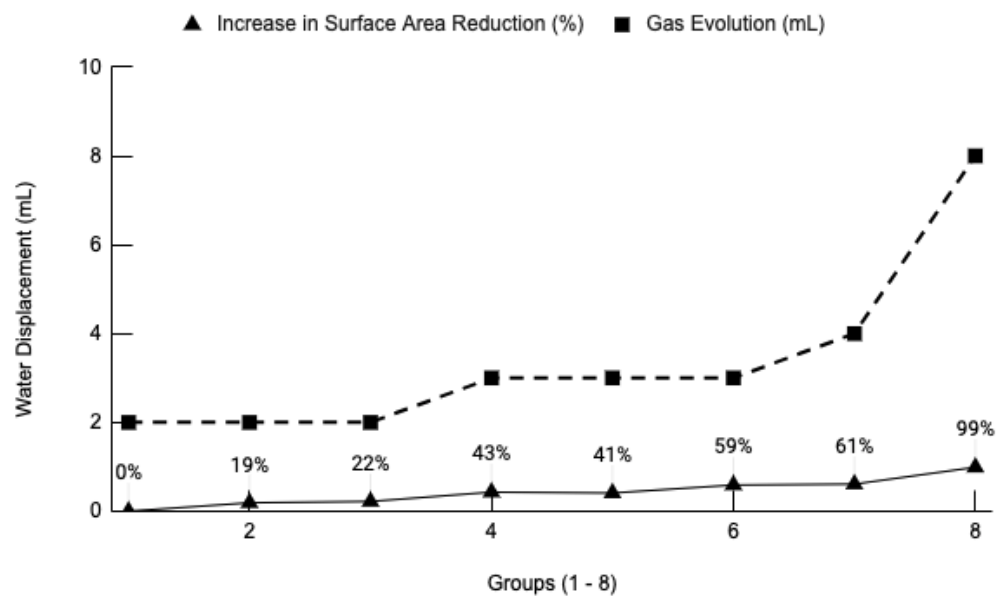

Figure 2. Surface area reduction and corresponding gas production (Groups 1-8).

An increased surface area loss of $14 \%$ was observed in samples pretreated by thermooxidation (Group 3) at $120{ }^{\circ} \mathrm{C}$. The procedure causes cross-linking, which breaks carbon-hydrogen bonds and gives rise to carbon-carbon single bonds. These tertiary sites have lower bonding energies and are therefore vulnerable points in LDPE morphology to extracellular enzymes [31].

Etching (Group 3) increased surface area reduction by $17 \%$ over a 6 day observation period. This result accompanies previous findings that on a molecular level, chemicaletching cleaves bonds in amorphous polymeric regions. The presence of citric acid may also be responsible for enhanced microbial activity by increasing surface bonding sites for hyphal extension and adding various polar groups [31]. 
An increase of $36 \%$ in surface area reduction was noted in leachate samples (Group 5). While the mechanism for this remains unclear, it is well-known that ligninolytic activity catalyzed by $P$. chrysosporium generally occurs in nitrogen-starved environments [32]. The SL-PDA growth media had a high C:N ratio, was sulfur-limited and phosphorus abundant, and contained $\mathrm{Mg}^{2+}$ and $\mathrm{Ca}^{2+}$, trace metals known to catalyze secondary metabolic responses in $P$. chrysosporium. Carbohydrate levels were also low. SL did contain abundant $\mathrm{NH}^{4+}$, but Jeffries et al. previously reported that it does not significantly suppress ligninolytic activity [28,33]. This leads to the following proposed mechanism: the synthetic composition of leachate met ligninolytic conditions, facilitating high levels of LDPE mineralization.

In conjunction, the three morphological treatments (Group 8) increased surface area reduction by a maximum of $99 \%$.

This data was corroborated by an analogous trend in gas evolution associated with fungal respiration and degradation products, quantified by water displacement in a pneumatic trough. Displacement in a sample with no fungal isolates was $0.7 \mathrm{~mL}$. Group 8 showed an $8 \mathrm{~mL}$ change in water level, and Ideal Gas Law calculations based on LDPE and SL composition approximately confirmed the surface area reduction results $[34,35]$.

\subsection{Electrospray Ionization Fourier Transform}

Figures 3, 4, and 5 show the FTMS + pESI profiles of SL, SL exposed to P. chrysosporium for 12 days, and SL with LDPE film exposed to $P$. chrysosporium for 12 days respectively.

Significant decreases were observed in the $\mathrm{CO}_{3}{ }^{2-}$ peak at $121.0278 \mathrm{~m} / z$ and $\mathrm{NH}_{4}{ }^{+}$ peak at $180.0859 \mathrm{~m} / z$ after 12 days of exposure. Heavy metal solubility appeared to rise. For example, $\mathrm{Mn}^{2+}$ at $350.9300 \mathrm{~m} / z$ can be observed in three unique peaks on Day 12. A number of organics were also observed in samples containing degraded LDPE products. ESI results suggested some signs of SL remediation, later confirmed by indicator tests for $\mathrm{NH}_{4}{ }^{+}, \mathrm{NO}_{3}{ }^{2-}$, and $\mathrm{NO}^{-}$. This aligns with conclusions drawn by previous research on $P$. chrysosporium metabolism and biodegradative potential for leachate [36-38]. 


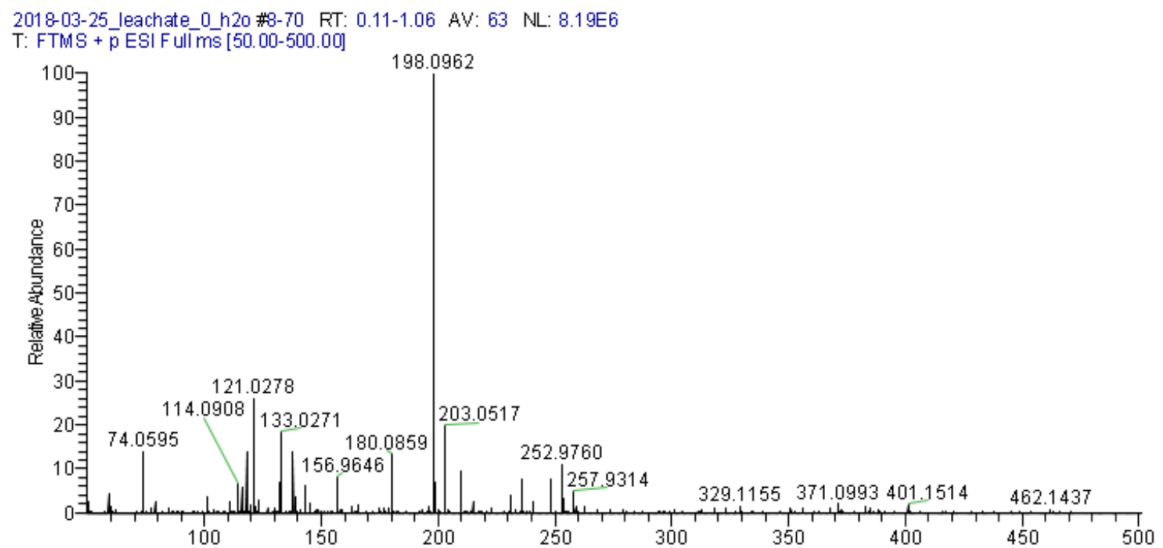

Figure 3. FTMS + pESI profile of Synthetic Leachate on Day 0.

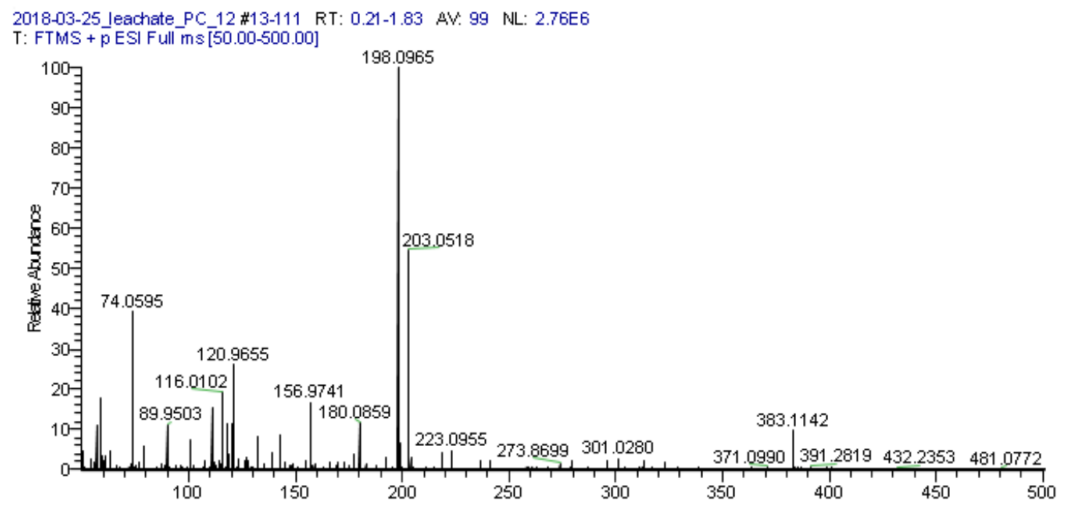

Figure 4. FTMS + pESI profile of Synthetic Leachate after 12 days of exposure to $P$. chrysosporium.

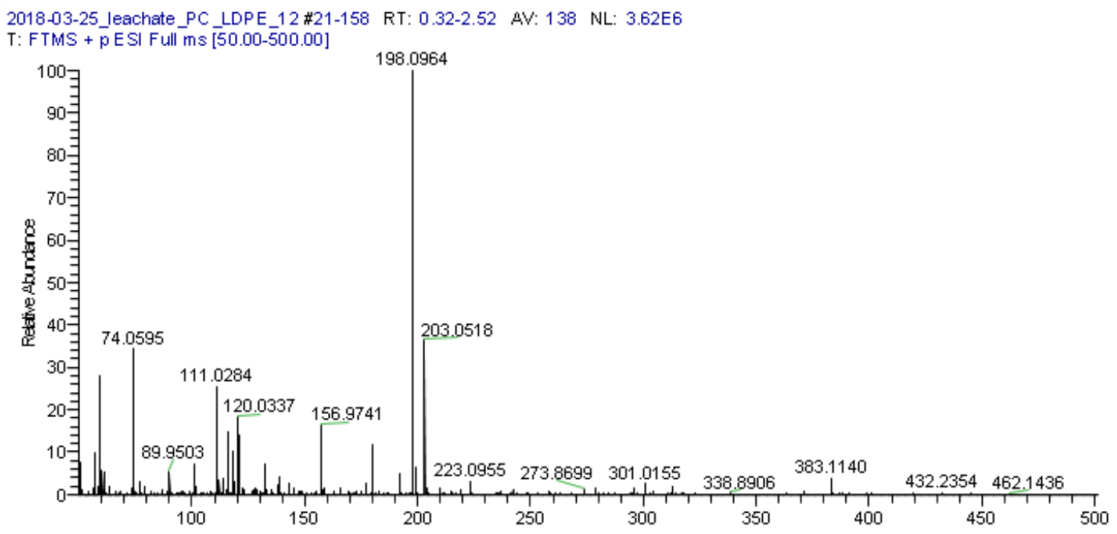

Figure 5. FTMS + pESI profile of Synthetic Leachate and degraded LDPE product after 12 days of exposure to $P$. chrysosporium. 


\section{Conclusions}

This study expands upon the limited body of research amalgamating physicochemical surface treatments and biodegradative approaches for effective mineralization. Surface area imaging revealed bioerosion, qualifying Phanerochaete chrysosporium as a suitable candidate for LDPE degradation. Trends in the crystallinity index over 6 days show that thermo-oxidation and chemical etching induced conformational changes to polymer surface morphology, and that crystallinity values decreased as a function of mycoremedial exposure. Thermo-oxidation was associated with a $19 \%$ increase in surface area reduction, etching showed a $22 \%$ increase, and synthetic leachate media showed a $36 \%$ increase. Together, they achieved a $99 \%$ increase in surface area reduction. These results were accompanied by a rise in gaseous evolution associated with $\mathrm{CO}_{2}$ and the respiration of fungal isolates. Therefore, the following molecular mechanism was proposed. Cross-linking and amorphous crystallization increased surface vulnerability to ligninolytic enzymatic activity, and $P$. chrysosporium secondary metabolites were produced in response to appropriate chemical conditions in leachate. FTMS + pESI profiles of leachate after 12 days of exposure to P. chrysosporium suggested signs of leachate mycoremediation: reductions in $\mathrm{CO}_{3}{ }^{2-}$ and $\mathrm{NH}_{4}{ }^{+}$levels, improved heavy metal solubility, and the presence trace organics were observed. This approach holds promise for attenuating challenges in LDPE disposal, especially in landfill structures.

\section{Acknowledgements}

The author thanks Drs. K. Walker and T. Hughes for technical guidance, along with the Department of Chemistry at Stanford University for ESI instrumentation. 


\section{References}

[1] Eric Beckman. The world's plastic problem in numbers. 2019.

[2] Charles Harper. Handbook of plastics technologies: The complete guide to properties and performance. 2006.

[3] Rinku Verma, KS Vinoda, M Papireddy, and ANS Gowda. Toxic pollutants from plastic waste - A review. Procedia Environmental Sciences, 35:701-708, 2016.

[4] Bhone Myint Kyaw, Ravi Champakalakshmi, Meena Kishore Sakharkar, Chu Sing Lim, and Kishore R Sakharkar. Biodegradation of low density polythene (ldpe) by Pseudomonas species.Indian journal of microbiology, 52(3):411-419, 2012.

[5] Haider, N., Karlsson, S. (1999). Migration and release profile of Chimassorb 944 from low-density polyethylene film (LDPE) in simulated landfills. Polymer degradation and stability, 64(2), 321-328.

[6] Hosoya, H., Miyazaki, N., Sugisaki, Y., Takanashi, E., Tsurufuji, M., Yamasaki, M., Tamura, G. (1978). Bacterial degradation of synthetic polymers and oligomers with the special reference to the case of polyethylene glycol. Agricultural and Biological Chemistry, $42(8), 1545-1552$.

[7] Sen, S. K., Raut, S. (2015). Microbial degradation of low density polyethylene (LDPE): A review. Journal of Environmental Chemical Engineering, 3(1), 462-473.

[8] Atefeh Esmaeili, Ahmad Ali Pourbabaee, Hossein Ali Alikhani, Farzin Shabani, and EnsiehEsmaeili. Biodegradation of low-density polyethylene (ldpe) by mixed culture of Lysinibacillus xylanilyticus and Aspergillus niger in soil.Plos one, 8(9):e71720, 2013.

[9] Jenkins, S. (2008). Characterising PET-degrading Ideonella Sakaensis and engineering of PETase through mutagenesis.

[10] Malachová, K., Novotný, Č., Adamus, G., Lotti, N., Rybková, Z., Soccio, M., ... Fava, F. (2020). Ability of Trichoderma hamatum Isolated from Plastics-Polluted Environments to Attack Petroleum-Based, Synthetic Polymer Films. Processes, 8(4), 467.

[11] Roy, P. K., Surekha, P., Raman, R., Rajagopal, C. (2009). Investigating the role of metal oxidation state on the degradation behaviour of LDPE. Polymer Degradation and Stability, 94(7), 1033-1039.

[12] Colleen Cripps, John A Bumpus, and Steven D Aust. Biodegradation of azo and heterocyclicdyes by Phanerochaete chrysosporium. Appl. Environ. Microbiol., 56(4):1114-1118, 1990.

[13] O Ben Hamman, T de La Rubia, and J Martinez. Effect of carbon and nitrogen limitation on lignin peroxidase and manganese peroxidase production by Phanerochaete flavidoalba.Journal of Applied Microbiology, 83(6):751-757, 1997

[14] Tien, M., Kirk, T. K. (1983). Lignin-degrading enzyme from the hymenomycete Phanerochaete chrysosporium Burds. Science, 221(4611), 661-663.

[15] Sahoo, S., Misra, M., Mohanty, A. K. (2011). Enhanced properties of lignin-based biodegradable polymer composites using injection moulding process. Composites Part A: Applied Science and Manufacturing, 42(11), 1710-1718.

[16] Ulises Urz ua, Philip J Kersten, and Rafael Vicu na. Manganese peroxidase-dependent oxidati onof glyoxylic and oxalic acids synthesized by ceriporiopsis subvermispora produces extracellular hydrogen peroxide.Appl. Environ. Microbiol., 64(1):68-73, 1998

[17] Tien, M., Kirk, T. K. (1988). Lignin peroxidase of Phanerochaete chrysosporium. Methods in enzymology, 161, 238-249.

[18] Francesca Bosco, Antonio Capolongo, and Bernardo Ruggeri. Effect of temperature, ph, ionic strength, and sodium nitrate on activity of lips: Implications for bioremediation. Bioremediation journal, 6(1):65-76, 2002.

[19] Khadar Valli, Barry J Brock, Dinesh K Joshi, and MH Gold. Degradation of 2, 4dinitrotoluene by the lignin-degrading fungus phanerochaete chrysosporium.Appl. Environ.Microbiol., 58(1):221-228, 1992.

[20] Jaqueline da Silva Coelho-Moreira, Adelar Bracht, Aline Cristine da Silva de Souza, Roselene Ferreira Oliveira, Anacharis Babeto de S a-Nakanishi, Cristina Giatti Marques de 
Souza,and Rosane Marina Peralta. Degradation of diuron by phanerochaete chrysosporium: role o fligninolytic enzymes and cytochrome p450. BioMed research international, 2013, 2013.

[21] Naresh Magan, Silvia Fragoeiro, and Catarina Bastos. Environmental factors and bioremedi-ation of xenobiotics using white rot fungi. Mycobiology, 38(4):238-248, 2010.

[22] Ayodeji O Falade, Uchechukwu U Nwodo, Benson C Iweriebor, Ezekiel Green, Leonard VMabinya, and Anthony I Okoh. Lignin peroxidase functionalities and prospective applications. Microbiology Open, 6(1):e00394, 2017.

[23] Kate M Drummond, Jefferson L Hopewell, and Robert A Shanks. Crystallization of lowdensity polyethylene and linear low-density polyethylene-rich blends. Journal of applied polymer sci-ence, 78(5):1009-1016, 2000

[24] Xiu-bin Zhang, Ze-sheng Li, Zhong-yuan Lu, and Chia-Chung Sun. The crystallization of low-density polyethylene: a molecular dynamics simulation. Polymer, 43(11):3223-3227, 2002.

[25] Jovan S Mijovic and James A Koutsky. Etching of polymeric surfaces: A review. PolymerPlastics Technology and Engineering, 9(2):139-179, 1977.

[26] Xu, P., Zeng, G. M., Huang, D. L., Lai, C., Zhao, M. H., Wei, Z., .. Xie, G. X. (2012). Adsorption of $\mathrm{Pb}(\mathrm{II})$ by iron oxide nanoparticles immobilized Phanerochaete chrysosporium: equilibrium, kinetic, thermodynamic and mechanisms analysis. Chemical Engineering Journal, 203, 423-431.

[27] Huang, S., Huang, D., Qitang, W. U., Meifang, H. O. U., Xiaoyan, T. A. N. G., Jian, Z. H. O. U. (2020). Effect of environmental C/N ratio on activities of lignin-degrading enzymes produced by Phanerochaete chrysosporium. Pedosphere, 30(2), 285-292.

[28] Azhar, A. H., Noor, N., Normah, A., Anuar, I. (2011). Ammonia and COD removal from synthetic leachate using rice husk composite adsorbent. Journal of Urban and Environmental Engineering (JUEE), 5(1), 24-31.

[29] Gałeski, A., Bartczak, Z., Pracella, M. (1984). Spherulite nucleation in polypropylene blends with low density polyethylene. Polymer, 25(9), 1323-1326.

[30] Miyagawa, E., Tokumitsu, K., Tanaka, A., Nitta, K. H. (2007). Mechanical property and molecular weight distribution changes with photo-and chemical-degradation on LDPE films. Polymer degradation and stability, 92(10), 1948-1956.

[31] Veitmann, M., Jumeau, R., Bourson, P., Ferriol, M., Lahure, F. (2014). Understanding and control of high temperature oxidation flaws of low-density poly (ethylene) with Raman spectroscopy. International Journal of Spectroscopy, 2014.

[32] Fenn, P., Kirk, T. K. (1981). Relationship of nitrogen to the onset and suppression of ligninolytic activity and secondary metabolism in Phanerochaete chrysosporium. Archives of Microbiology, 130(1), 59-65.

[33] Jeffries, T. W., Choi, S., Kirk, T. K. (1981). Nutritional regulation of lignin degradation by Phanerochaete chrysosporium. Applied and Environmental Microbiology, 42(2), 290296.

[34] S Levine. Derivation of the Ideal Gas Law. Journal of Chemical Education, 62(5):399, 1985

[35] Pramila, R., Ramesh, K. V. (2011). Biodegradation of low density polyethylene (LDPE) by fungi isolated from municipal landfill area. J. Microbiol. Biotechnol. Res, 1(131), e136.

[36] Hu, L., Zeng, G., Chen, G., Dong, H., Liu, Y., Wan, J., ... Yu, Z. (2016). Treatment of landfill leachate using immobilized Phanerochaete chrysosporium loaded with nitrogendoped $\mathrm{TiO} 2$ nanoparticles. Journal of hazardous materials, 301, 106-118.

[37] Hu, L., Liu, Y., Zeng, G., Chen, G., Wan, J., Zeng, Y., ... Cheng, M. (2017). Organic matters removal from landfill leachate by immobilized Phanerochaete chrysosporium loaded with graphitic carbon nitride under visible light irradiation. Chemosphere, 184, 1071-1079.

[38] Kim, Y. K., Park, S. K., Kim, S. D. (2003). Treatment of landfill leachate by white rot fungus in combination with zeolite filters. Journal of Environmental Science and Health, Part A, 38(4), 671-683. 